www4.fsanet.com.br/revista

e-revist@s

ISSN Impresso: 1806-6356 ISSN Eletrônico: 2317-2983

http://dx.doi.org/10.12819/2021.18.03.1

\title{
Consumidor da Terceira Idade: Estudo Bibliométrico dos Artigos Publicados no Brasil
}

Elderly Consumers: A Bibliometric Study of Articles Published in Brazil

Mirian Cristina Vidal da Rocha

Mestra em Gestão e Estratégia em Negócios pela Universidade Federal Rural do Rio de Janeiro Tutora no Tecnólogo em Gestão do Turismo no CEFET

E-mail:mirianala@yahoo.com.br

Renata Celi Moreira da Silva Paula

Doutora em Administração pela Pontifícia Universidade Católica do Rio de Janeiro Profa. Adjunta da Faculdade de Administração - UFF E-mail: renata.celi@gmail.com

Fábio Francisco de Araújo

Doutor em Administração de Empresas pela Pontifícia Universidade Católica do Rio de Janeiro Professor Adjunto de Gestão de Serviços da Universidade Federal do Rio de Janeiro

E-mail: fabiofdearaujo@gmail.com

Maria Cristina Drumond e Castro

Doutora em Ciência Tecnologia e Inovação em Agropecuária pela Universidade Federal Rural do Rio de Janeiro Professora do Quadro Permanente do Mestrado em Gestão \& Estratégia da UFRRJ

E-mail: cristina.ufrrj.itr@gmail.com

André Luís Faria Duarte Doutor em Administração pela Universidade do Grande Rio Analista em C\&T na Comissão Nacional de Energia Nuclear E-mail: alduarte@cnen.gov.br

Endereço: Mirian Cristina Vidal da Rocha

Av. Maracanã, 229 - Maracanã - Rio de Janeiro/RJ, Brasil.

Endereço: Renata Celi Moreira da Silva Paula

Av. Aluízio da Silva Gomes, 50 - Granja dos Cavaleiros, Macaé - RJ, 27930-560, Brasil.

Endereço: Fábio Francisco de Araújo

UFRRJ - Centro de Ciências da Saúde, Instituto de Nutrição Josué de Castro, CCS - Centro de Ciências da Saúde - Av. Carlos Chagas Filho, 373, 21941902 - Rio de Janeiro, RJ Brasil.

Endereço: Maria Cristina Drumond e Castro

Av. Pref. Alberto da Silva Lavinas, 1847 - Três Rios, RJ, 25802-100, Brasil.

Endereço: André Luís Faria Duarte

Rua Gal. Severiano, nº 82, Botafogo, CEP: 22290-901 -

Editor-Chefe: Dr. Tonny Kerley de Alencar Rodrigues

Artigo recebido em $08 / 02 / 2021$. Última versão recebida em 22/02/2021. Aprovado em 23/02/2021.

Avaliado pelo sistema Triple Review: a) Desk Review pelo Editor-Chefe; e b) Double Blind Review (avaliação cega por dois avaliadores da área).

Revisão: Gramatical, Normativa e de Formatação Rio de Janeiro - RJ, Brasil. 


\title{
RESUMO
}

O estudo analisou as publicações no campo do comportamento do consumidor da terceira idade no Brasil. Para isso, foi realizada uma análise bibliométrica. As fontes para coleta dos artigos foram os anais dos Encontros da Associação Nacional de Pós Graduação e Pesquisa em Administração (EnANPAD) e as revistas nacionais classificadas no Qualis administração como A1, A2 e B1 no período de 2008 a 2017. Foram feitas as seguintes análises: evolução quantitativa da publicação de artigos sobre o consumidor da terceira idade; mapeamento das instituições e autores que produziram sobre o consumidor da terceira idade; mapeamento dos artigos publicados por somente um autor ou em coautoria; mapeamento das abordagens metodológicas utilizadas nos artigos; e análise das temáticas investigadas. Como resultados, foi identificado um grande aumento no número de artigos dessa temática em 2017, principalmente no EnANPAD, cuja área de turismo se destaca na produção acadêmica sobre o consumidor da terceira idade no Brasil, e que a abordagem mais utilizada foi a qualitativa.

Palavras-chave: Comportamento do Consumidor. Consumidor de Terceira Idade. Estudo Bibliométrico. Produção Científica.

\begin{abstract}
The study analyzed publications in the field of consumer behavior in the elderly in Brazil. For this, a bibliometric analysis was performed. The sources for collecting the articles were the annals of the Meetings of the National Association of Graduate Studies and Research in Administration (EnANPAD) and the national journals classified in Qualis Administração as A1, A2 and B1 in the period from 2008 to 2017. The following analyzes were made: quantitative evolution of the publication of articles on the elderly consumer; mapping of the institutions and authors that produced about the elderly consumer; mapping of articles published by only one author or in co-authorship; mapping of the methodological approaches used in the articles; and analysis of the investigated themes. As a result, a large increase in the number of articles on this theme was identified in 2017, mainly in EnANPAD, that the tourism area stands out in academic production on the elderly consumer in Brazil, and that the most used approach was the qualitative one.
\end{abstract}

Keywords: Consumer Behavior. Elderly Consumer. Bibliometric Study. Scientific Production. 


\section{INTRODUÇÃO}

O envelhecimento da população proporcionado pelos avanços tecnológicos na área de saúde tem proporcionado o prolongamento da vida das pessoas. Há pouco tempo, os indivíduos com idade avançada eram reconhecidos como pessoas que chegavam à velhice, uma fase de vida improdutiva ligada ao descanso, invalidez e doenças. Nos últimos anos, esse período da vida sofreu uma grande transformação, passando a ser chamado de terceira idade e sendo conhecido como uma fase para desfrutar a vida (ARAUJO; ROCHA, 2016; SILVA, 2008). Essa denominação passa a significar “o momento do lazer, propício à realização pessoal que ficou incompleta na juventude, à criação de novos hábitos, hobbies e habilidades e ao cultivo de laços afetivos e amorosos alternativos à família” (SILVA, 2008, p. 161).

O envelhecimento da população é enfrentado pela maioria dos países desenvolvidos. Fabricius e Eriksson (2017) citam estudos que mostram essa questão, como, por exemplo, um estudo que aponta que a proporção da população na Finlândia de pessoas na terceira idade deve aumentar de $18 \%$ para $26 \%$ até o ano de 2030 . Os autores mencionam que o público idoso é o que mais tem crescido no mundo. Babin, Zhuang e Borges (2021) afirmam que a população mundial está envelhecendo rapidamente.

No Brasil, $21 \%$ da população têm 50 anos ou mais, sendo $27 \%$ mulheres entre 55 e 70 anos, devendo passar a 32 milhões no ano de 2025 (IBGE, 2010). O aumento na expectativa de vida das pessoas e a redução na taxa de natalidade têm trazido transformações na sociedade. Tomas e Peters (2009) ressaltam que os consumidores idosos continuam ativos física e socialmente, constituindo um mercado importante para as empresas.

Pak e Kambil (2006) esclarecem que as transformações sofridas pela terceira idade (transformações no corpo, transformações biológicas, dentre outras) influenciam as diversas relações desse grupo e, dessa forma, geram impactos em suas vidas. Todas essas alterações têm reflexo na maneira como o consumidor na terceira idade consome produtos e serviços. É importante compreender esse grupo de consumidores na terceira idade e reconhecê-los como força econômica, já que se trata de um mercado consumidor com grande poder de compra (TOMAS; PETERS, 2009).

Esse tema vem sendo estudado nos campos da psicologia, medicina, sociologia, administração, marketing, consumo, entre outros, e, devido à perspectiva contemporânea, novos desafios e debates caracterizam essa discussão. Nikou (2015) e Fabricius e Eriksson (2017) ressaltam que um segmento de consumo que tem chamado a atenção dos 
pesquisadores é o que engloba os indivíduos com idade entre 60 e 75 anos, pois são considerados os "jovens idosos".

A classe média urbana na década de 60 e 70 começa a usufruir da aposentadoria. Esse grupo começa a ter uma demanda específica e pouco conhecida, quando começam a aparecer estudos de especialistas de ciências humanas que passam a identificar e descrever esses sujeitos enquanto aspiração e necessidade de consumo (SILVA, 2008). Para Swimberghe et al. (2018), os consumidores idosos representam um segmento particularmente relevante e lucrativo. Assim, as empresas precisam oferecer experiências de consumo satisfatórias que atraiam consumidores idosos como forma de manter ou aumentar sua participação no mercado (BABIN; ZHUANG; BORGES, 2021).

Neste contexto, necessita-se de pesquisas para investigar e entender melhor esse processo de transformação. É preciso aprofundar as questões ligadas ao consumidor da terceira idade. Sendo assim, surgem questões que carecem de resposta: Existem pesquisas sobre o consumidor da terceira idade no Brasil? Como essas pesquisas estão evoluindo? Existem temas específicos mais estudados sobre o consumidor da terceira idade? Quais são as universidades e os pesquisadores que mais publicam artigos científicos sobre o assunto?

Compreender essa transformação de que tratam as pesquisas sobre o envelhecimento contemporâneo é o que motiva esse estudo, que visa a investigar a produção no campo do consumidor da terceira idade no Brasil. Assim, os resultados desta pesquisa buscam contribuir para compreender mais profundamente este segmento e para inclusão desse grupo de consumidores na pesquisa de consumo. Levantar os artigos científicos já publicados sobre o assunto parece necessário e oportuno para mapear a produção científica nesta área de conhecimento. Por conseguinte, o objetivo do presente artigo é realizar uma análise dos estudos publicados sobre o consumidor da terceira idade no período de 2008 a 2017 nos congressos da Associação Nacional de Pós-graduação e Pesquisa em Administração (ANPAD) e nas revistas acadêmicas brasileiras de Administração classificadas na lista Qualis da CAPES - Coordenação de Aperfeiçoamento de Pessoal de Nível Superior, com classificações entre A1 a B1. 


\section{REFERENCIAL TEÓRICO}

\subsection{Evolução da construção social da noção de Terceira Idade}

Janmohamed e Lloyd (1990) sublinham que os grupos sociais são constituídos e reproduzidos no discurso e na prática das atividades humanas, ficando inseridos em uma estrutura hierárquica. As classificações das faixas etárias mostram semelhante estrutura hierárquica, que emerge como resultado de determinado contexto histórico e social. Fennell, Phillipson e Evers (1988) apontam que a comunidade médica ocidental começou a estudar a velhice sob a égide da patologia a partir do século XX, considerando a velhice como a perda do funcionamento físico e mental, em contrapartida do estado considerado "normal", que tem como paradigma o estado físico e mental dos jovens adultos.

Nos Estados Unidos, depois dos anos 1960, a situação de marginalização da população idosa ficou mais crítica com a popularização da teoria levantada por Cumming e Henry (1961), a qual defendia que as pessoas, ao chegarem a idades avançadas, tenderiam a se isolar como forma de se preparar para a morte. Nesse âmbito, a velhice era compreendida como um tempo de solidão. Além disso, segundo Binstock (2005), naquele país, a legislação em vigor à época dava conta de que os idosos eram pessoas financeiramente necessitadas e vulneráveis a doenças, sendo preciso a aprovação, em 1965, da Lei Medicare, que previa uma proteção especial para pessoas idosas em relação à saúde.

Apesar de essa marginalização ser verificada em estudos sobre indivíduos de mais idade no século passado, hoje, entretanto, é possível observar que ainda persiste a ideia de que a população de terceira idade é um grupo de indivíduos em condição mais debilitada da vida. Segundo Gullette (2004), em muitos casos, é comum que a população idosa seja retratada, do ponto de vista social, como cognitiva e fisicamente inferior. Cuddy, Norton e Fiske (2005) chamam a atenção para outras formas de estereótipos em relação à população de terceira idade, tais como falta de flexibilidade, falta de produtividade, maior sujeição ao desamparo, senilidade, debilidade e até letargia.

Vesperi (2004) apontou que a indústria do entretenimento audiovisual também marginalizou os indivíduos de terceira idade, omitindo-os de programas, seriados e filmes. Em 2003, por exemplo, menos de 3\% dos personagens de ficção produzida nos Estados Unidos para televisão e para cinema representavam indivíduos com mais de 65 anos.

Em sentido oposto, Gergen e Gergen (2000) defendem que a visão negativa em relação ao envelhecimento está chegando ao fim. Segundo os autores, já existe o 
reconhecimento de que o envelhecimento pode se dar de forma positiva, uma vez que as pessoas estão vivendo mais e manifestando seu poder, seja do ponto de vista da proficiência e manutenção da habilidade, seja do ponto de vista econômico. Nesse sentido, a ideia de que o idoso é dependente e debilitado estaria sendo gradativamente desconstruída. A participação ativa em atividades sociais, físicas, tecnológicas ou de aprendizado etc., vem desmentindo o entendimento de que as limitações da idade necessariamente colocam o idoso em situação de desvantagem em relação aos jovens e aos adultos, fato que tem despertado para a noção trazida por Gergen e Gergen (2000) do envelhecimento positivo.

Lins de Barros (2013) defende a existência de uma "ideologia da terceira idade", que caminha em sentido oposto à antiga e estigmatizada noção de velhice. Segundo a autora, o atual conceito de "Terceira Idade" remete a uma ideia - nascida de uma construção ideológica - que se caracteriza por meio de um envelhecimento ativo. Nesse contexto, os idosos de mais idade são percebidos como indivíduos que podem abraçar novos projetos de vida desde que adequados a esta etapa da vida, podem também assumir o cuidado de si mesmo e podem ainda assumir a responsabilidade pessoal da condução de sua própria vida. Assim, o conceito contemporâneo de Terceira Idade não remonta à lógica da velhice como fator impeditivo e limitador, mas assume uma lógica de envelhecimento ativo, na qual o idoso é compreendido como um indivíduo capaz e autônomo para realizar e administrar suas escolhas, sendo considerado habilitado para atuar no contexto social de modo satisfatório.

Goldenberg (2011), em seus estudos, observou que a velhice é uma etapa da vida em que se têm perdas e ganhos pessoais. Segundo a autora, quando chegam à terceira idade, os indivíduos tendem a sentir-se mais livres das pressões sociais, lançando o seu foco para as atividades que mais lhe dão prazer e que realmente gostam ou gostariam de fazer. Dessa forma, na velhice, as pessoas estão mais abertas para se descobrirem a partir das experiências que se permitem viver, conhecer mais profundamente os seus próprios desejos e vontades e, quando conseguem, optam por priorizar apenas o que pode trazer a sensação de felicidade.

Segundo Debert (2004), é nesse contexto que surge a noção da terceira idade. A autora pontua que o surgimento dessa designação está relacionado a uma tentativa de estabelecer uma nova imagem para esta etapa da vida. Debert (2004) sugere que essa noção sobre o envelhecimento emerge com o objetivo de combater estereótipos e concepções discriminatórias já consolidadas na designação "idoso". Desse modo, ao introduzir a designação terceira idade, há a concepção de um novo ethos para esta fase da vida, o qual pretende superar a noção da velhice como uma fase de fragilização física e social do indivíduo. Debert (2004) sublinha que ao se mitigarem as imagens negativas das 
representações da Terceira Idade obtém-se o que chamou de elemento ativo na reprivatização do envelhecimento, o qual contribui para a elevação do status do corpo saudável, representado pela imagem física de uma pessoa jovem, como elemento constituinte da identidade do indivíduo (jovem, adulto ou idoso) na esfera pública, o que chamou de discurso do "envelhecimento positivo".

Ao refletir como as classificações sociais são determinadas para pontuar a posição ocupada por um indivíduo no grupo social, observa-se a influência dos valores socialmente construídos para demarcar os indivíduos em determinado contexto. O estudo de Hall (1997) mostra como as pessoas em diferentes classes sociais são definidas e classificadas em relação a outras em razão do discurso e da prática, incluindo as práticas de consumo. Nesse sentido, Acuña (2004) estudou os efeitos de ser posicionado e tratado como um membro de um grupo étnico minoritário desvalorizado. Percebe-se, assim, que os indivíduos buscam se posicionar como pertencentes a uma classe socialmente construída, bem como se atribuírem a pertinência a essa classe, por si mesmos e pelos outros. Dessa forma, produzem categorias sociais a que são associadas certas capacidades e características de outros. Por exemplo, a noção de "Terceira Idade" é uma construção social da posição do indivíduo, que outros podem usar em seu discurso para se referir ao idoso como socialmente inferior. Isso pode ocorrer, por exemplo, ao se adotar discurso com tom infantilizado ao conversar com um idoso (ARAUJO et al., 2015), ou mesmo em práticas como ajudá-lo a caminhar ou a executar tarefas (BARNHART; PEÑALOZA, 2013).

\subsection{Temas de Investigação em Comportamento do Consumidor na Terceira Idade}

A disciplina de marketing tem dado pouca atenção ao idoso como consumidor. Migdał-Najman, Najman e Badowska (2020) sustentam que o mercado de idosos ainda está em um estágio inicial de conhecimento mais abrangente, tanto para acadêmicos quanto para profissionais. Destaca-se, entretanto, que os estudiosos de marketing têm contribuído para a construção da noção de Terceira Idade como se o idoso estivesse em uma posição marginalizada e desvalorizada. Por exemplo, o Modelo de Ciclo de Vida (FLC) de Wells e Gubar (1966) reproduz os estereótipos negativos da velhice, isolamento e solidão anteriormente avançado por Cumming e Henry (1961), ao intitular fases da velhice como "ninho vazio" e "sobrevivente solitário". Mais tarde, como nas atualizações para o modelo de Gilly e Enis (1982) e Murphy e Staples (1979), os consumidores idosos continuaram a ser segmentados como consumidores solteiros ou casados, em vez de classificados como 
membros do grupo, o que pode se dever ao foco sobre o consumo das famílias na segmentação de consumidores adultos (PETER; OLSON, 2009).

Os primeiros estudos sobre as práticas de consumo na terceira idade - assim como parte importante da literatura subsequente - focavam as restrições deste grupo para realizar plenamente o seu papel de consumidor. Alexandris e Carroll (1997) relacionam tais restrições ao efeito idade e ao ciclo de vida, os quais se revelam como interferências peculiares ao contexto de decisão do consumidor. Para Fleischer e Pizam (2002), as restrições físicas e intrapessoais aumentam significativamente com a idade, pois, com o avanço da idade, mais deterioradas tornam-se as condições de saúde. As pessoas passam por transformações ao envelhecerem, as quais representam, em sua maioria, mudanças biológicas naturais ao envelhecimento (OBERG; TORNSTAM, 1999). Essas transformações naturais podem afetar sua mobilidade, flexibilidade, elasticidade, força, visão e audição, o que impacta suas relações sociais, profissionais e familiares e sua forma de consumir (PAK; KAMBIL, 2006). De acordo com o estudo de Hoeymans et al. (1997), as pessoas idosas tendem a perder suas habilidades funcionais com o passar dos anos, mas a saúde e a capacidade de avaliação do contexto não necessariamente diminuem com o passar do tempo. Mesmo assim, embora parte dos idosos apresente limitações físicas, não se pode generalizar essa condição para toda a população da Terceira Idade. No entanto, a maior parte dos produtos vendidos especificamente para os idosos ainda está relacionada à ideia de incapacidade de locomoção ou condição física limitada (ARAUJO; ROCHA, 2017).

Os estudos na literatura que abordam limitações dos idosos abarcam diferentes temas. O estudo de Mattila, Karjaluoto e Pento (2003) buscou conhecer o comportamento dos idosos em relação aos serviços bancários, notadamente no que diz respeito à introdução dos serviços de autoatendimento. Os resultados mostram que os idosos sempre que possível optam por dispensar o autosserviço e preferem ser atendidos ou assistidos por funcionários, em razão das dificuldades de interação com equipamentos automatizados. Kennett, Moschis e Bellenger (1995) observaram dificuldades parecidas em relação aos serviços financeiros disponíveis para investimento de sua renda.

O estudo de Burt e Gabbott (1995) analisou o comportamento do consumidor idoso em relação à compra de alimentos. Os autores observaram que os idosos eram praticamente ignorados enquanto consumidores. Esse fato foi considerado pelos pesquisadores um comportamento inadequado e ingênuo, pois não se pode ignorar sua influência no contexto familiar para compra dos alimentos consumidos pela família. Eles identificaram como principais fatores que impactam a escolha dos alimentos por consumidores idosos a influência 
da idade no estilo de vida, a relação entre as expectativas do consumidor idoso e os atributos da loja, e a relação de clientela com lojas próximas de casa.

\subsection{Segmentos da Terceira Idade}

O ambiente possui diversos aspectos que podem influenciar o comportamento, a cognição e as respostas afetivas dos indivíduos em relação ao consumo (AHUVIA, 2005). Além do ambiente físico, o ambiente social impacta fortemente as decisões de consumo. Os indivíduos fazem parte de diferentes grupos sociais, em que seu comportamento de consumo observável pode influir no desejo de compra uns dos outros. Isso ocorre por meio de interações sociais, nas quais os consumidores podem interagir com outros diretamente em conversas, trocas de ideias, partilhas de interesse etc., ou indiretamente por meio de observação de como se comportam os outros no contexto social. Nesse sentido, Fontenla e Almeida (2020, p. 750), ao pesquisarem sobre consumo de serviços de lazer pela terceira idade, identificaram que:

[...] os fatores gerados pelo boca a boca positivo, como segurança, engajamento, alívio, obtenção de conhecimento, rede social, confiança, expectativa positiva e entusiasmo, parecem ser fortes e são fundamentais para o processo de decisão de compras pelos consumidores da terceira idade.

Peter e Olson (2009) destacam que, entre as diferentes possibilidades de influência do ambiente social no comportamento do consumidor, estão as influências culturais, transculturais, subculturais e de classe social. Para esta pesquisa, é interessante discutir as subculturas etárias. De acordo com o autor, os grupos etários tendem a ser analisados em marketing como subculturas distintas, porque normalmente têm valores e comportamentos distintos em várias áreas da vida. Contudo, como colocado por Debert (1997), é preciso cautela com relação à segmentação dos consumidores de Terceira Idade apenas com base em sua idade real. Esse fenômeno ocorre em razão da noção de autoconceito de juventude, segundo o qual o indivíduo tem uma idade psicológica diferente da idade cronológica. Um exemplo interessante nessa direção pode ser extraído de uma pesquisa norte-americana, em que aparece o depoimento de uma idosa, citado por Peter e Olson (2009, p. 317), quando falavam de subculturas etárias:

Posso ter 89 anos de idade, mas me sinto bem. Eu me sinto como se pudesse sair por aí. É sério. Eu me sinto mais jovem, como se tivesse 45 ou 50 anos. 
Tenho vontade de me arrumar e gosto de agitação... Não me sinto velha. Acho que vou viver por muito tempo.

Peter e Olson (2009, p. 320) destacam que, em relação à população de terceira idade, tem-se um grupo de consumidores de grande importância econômica, mas que se caracteriza por ser um "mercado extremamente diversificado".

Segundo Schewe e Carlson (2003), os pesquisadores de marketing têm negligenciado realizar uma segmentação mais precisa em função da idade, pois apesar de um indivíduo ser considerado idoso, ele pode ter necessidades diferenciadas de outros também considerados idosos. Isso decorre de diversas razões, entre as quais as diferentes faixas de idades abarcadas pela terceira idade e, até mesmo, diferenças de geração. Ao longo da vida, os indivíduos tendem a criar valores construídos socialmente juntamente com sua geração, que podem permanecer inalterados. Indivíduos de uma dada geração, ao ingressarem na terceira idade, podem apresentar valores e interesses diferentes de outros grupos de idosos, o que exige, por parte dos profissionais de marketing, o entendimento das diferenças dentro do segmento de idosos. Nesse sentido, o mercado de idosos não deve ser considerado homogêneo, tendo segmentos e microssegmentos específicos que podem ser identificados em função do comportamento de compra (MIGDAŁ-NAJMAN; NAJMAN; BADOWSKA, 2020). Para Pannhorst e Dost (2019), um mercado de idosos fragmentado e em evolução oferece amplo potencial para especializações, segmentações e nichos.

De acordo com Castro (1989), os consumidores de terceira idade não são fáceis de atrair e, dessa forma, as empresas precisam conhecer melhor esse grupo. Muitos profissionais de marketing assumem que este grupo é basicamente composto de indivíduos frágeis, inflexíveis e pouco ativos. Entretanto, Castro (1989) alerta para o fato de que tal visão é um mito. Ao contrário, os idosos estão conseguindo permanecer ativos e saudáveis por longo tempo. Essa realidade lhes permite viver melhor a vida e participar de atividades que há pouco tempo eram direcionadas a outros segmentos populacionais. Swimberghe et al. (2018) sustentam que, para atrair consumidores idosos, é preciso compreender seus objetivos e aspirações, e ressaltam que, no passado, a publicidade retratava os idosos em estado de desamparo ou fragilidade, mas que pode ser mais produtivo comunicar os triunfos em vez dos traumas da maturidade. 


\subsection{Práticas de Consumo na Terceira Idade}

Estudos mais recentes sobre a tomada de decisão dos consumidores de Terceira Idade dão conta de temas tais como capacidade cognitiva (COLE et al., 2008; NASCO; HALE, 2009; WILLIAMS; DROLET, 2005), interesses e necessidades de compra (MYERS; LUMBERS, 2008; PETTIGREW; MIZERSKI; DONOVAN, 2005) e lealdade e escolha de marca (LAMBERT-PANDRAUD; LAURENT, 2010). Entretanto, todas estas pesquisas se baseiam na suposição de que a velhice afeta a forma como as pessoas consomem, o que não é necessariamente verdade, como observado por Barnhart e Peñaloza (2013). Ao suporem que a velhice modifica o consumo, os pesquisadores deixam de considerar e questionar de que maneira os idosos compreendem a velhice e como consomem a partir de sua própria visão enquanto sujeitos ativos de consumo. Dessa forma, Barnhart e Peñaloza (2013) defendem que é preciso entender como as pessoas de Terceira Idade realizam suas escolhas de consumo a partir de suas próprias perspectivas e interesses.

Ao atingirem idade mais avançada, os consumidores começam a preocupar-se com a utilização de seu tempo e procuram atividades que preencham o tempo livre e que constituam novas experiências. Muitos idosos se dão conta de que há muito para se viver e procuram participar do maior número possível de atividades em seu tempo livre (DOLL, 2007).

Estudos mais recentes sugerem que esses consumidores também podem estar mais abertos a experimentar novidades nessa fase da vida, como viagens a lazer (HORNEMAN et al., 2002), praticar atividades que permitam mais convivência com amigos, independência da família, aprendizado e autorrealização (BIRTWISTLE; TSIM, 2005; MYERS; LUMBERS, 2008). A constatação dessa tendência pode marcar uma nova forma de enxergar os consumidores de terceira idade, não apenas a partir de necessidades relacionadas ao cuidado com a saúde.

Araujo e Rocha (2016) desenvolveram um estudo no qual observaram que indivíduos de Terceira Idade que se reúnem em grupo de seresta para ouvirem e cantarem nos encontros musicais emergem como cocriadores de suas atividades de lazer. Nesse sentido, os próprios idosos assumem um posicionamento ativo na construção subjetiva de significados e na forma pela qual tais significados ressignificam a Terceira Idade na perspectiva dos próprios idosos. Em estudo mais recente, no qual os autores analisaram a prática de consumo de lazer em um grupo de dança de salão, Araujo e Rocha (2017) sublinham que as práticas de lazer na Terceira Idade refletem o resgate da autonomia subjetiva do indivíduo. A pesquisa oferece 
uma visão dinâmica do processo de atribuição, transferência e negociação de significados que decorrem da produção de sentidos atribuídos às atividades de lazer.

Já Alves (2003) realizou outro estudo etnográfico voltado para a participação em bailes frequentados por mulheres mais velhas. O objetivo era estudar as relações de gênero em contextos de sociabilidade, analisando diferentes faixas etárias e diferentes classes sociais. A pesquisa concluiu que o baile implica uma reversão de papéis, em que as mulheres mais velhas pagam homens mais jovens e de classe social mais baixa (dançarinos) para dançar com elas e, por consequência, passam a ter o controle sobre com quem e quando vão dançar.

Burnett-Wolle e Godbey (2007) investigaram as relações entre comportamento na Terceira Idade e lazer. Os resultados mostraram que indivíduos mais velhos usavam o lazer para se adaptar às mudanças na vida adulta e suas fontes sociais de apoio. O lazer emergiu como um importante caminho para demarcar independência e realizar interação social. A socialização também aparece como valor importante para os idosos no estudo de outros pesquisadores do assunto. Para Barnhart e Peñaloza (2013), o comportamento de consumo do idoso é fortemente impactado pela experiência compartilhada por amigos e pessoas com quem interage. O grupo de referência aparece como fonte relevante para escolhas e decisões de consumo e como alternativa à influência de familiares e de cuidadores, remetendo ao desejo do idoso de realizar suas próprias escolhas de consumo.

\section{METODOLOGIA}

O presente artigo tem como objetivo analisar a produção científica brasileira sobre o comportamento do consumidor da terceira idade. Trata-se de um estudo bibliométrico, que busca analisar as atividades científicas por intermédio de estudos quantitativos (SANTOS, 2003). A pesquisa se caracteriza, quanto aos fins, como descritiva e exploratória. Descritiva pois busca descrever as características de determinada população ou fenômeno (GIL, 2008), e exploratória, já que tem como intenção familiarizar-se com um fenômeno (CERVO; BERVIAN; DA SILVA, 2007).

As investigações bibliográficas foram iniciadas com uma análise na base de dados dos eventos científicos da ANPAD e das revistas científicas nacionais classificadas na lista Qualis de Administração da CAPES como A1 a B1.

A coleta e a análise de dados foram divididas em quatro etapas: Etapa 1: Identificação das revistas e eventos da ANPAD; Etapa 2: Pesquisa na base de dados para coletar os artigos; 
Etapa 3: Seleção dos artigos que atendiam à temática do estudo; Etapa 4: Classificação e análise dos artigos.

Em primeiro lugar foram selecionados os eventos científicos da ANPAD para fazer a busca dos artigos sobre a temática do comportamento do consumidor da terceira idade. Os eventos considerados foram o EMA - Encontro de Marketing da ANPAD e o EnANPAD Encontro da ANPAD, que possui uma área de publicação para Marketing e Comportamento do Consumidor. Foram também identificadas as revistas brasileiras de Administração classificadas como A1, A2 e B1.

A coleta dos artigos científicos publicados no Brasil sobre o consumidor idoso foi feita por meio de busca na base de dados dos veículos selecionados. A busca realizou-se com a utilização das palavras-chave "idoso(s)", "terceira idade", “envelhecimento", "maduro(s)"/"madura(s)" e "grisalho". Dessa forma, buscou-se contemplar todos as possíveis publicações sobre a temática. O termo consumidor "maduro(a)" só foi considerado para artigos que incluíam o segmento da terceira idade. Os artigos sobre consumidor maduro cuja idade ainda não era considerada no segmento idoso não foram considerados.

Em seguida, cada artigo coletado foi analisado para verificar se englobavam a temática consumo e consumidor na terceira idade no Brasil. Alguns artigos que apareceram nas buscas na base de dados não abordavam especificamente a área de conhecimento do consumo e consumidor idoso e, por isso, não foram incluídos dentre os artigos considerados no presente estudo.

Curiosamente, surgiu nas buscas da base de dados do site da ANPAD um artigo do EnGPR - Encontro de Gestão de Pessoas e Relações de Trabalho que abordava o consumidor idoso. Sendo assim, este congresso também foi considerado, além do EnANPAD e do EMA. Em relação ao EnANPAD, foram considerados os artigos da área de interesse Marketing e os artigos de outras áreas que também abordavam a temática de consumo da terceira idade.

Vale ressaltar que ocorreu também a duplicidade de algumas publicações em congresso e em revista. Nestes casos, optou-se por considerar a publicação na revista, excluindo a publicação dos congressos para eliminar o problema da duplicidade.

No total, foram selecionados 35 artigos para o presente estudo, como pode ser visto no Quadro 1, a seguir. Os artigos estão listados em ordem cronológica do ano mais recente para o período mais antigo. 
Quadro 1 - Artigos selecionados

\begin{tabular}{|c|c|c|}
\hline Meio de publicação & Ano & $\begin{array}{l}\text { Título do artigo } \\
\end{array}$ \\
\hline EnANPAD & 2017 & $\begin{array}{c}\text { Uma Perspectiva Transformadora Entre Consumidores Idosos } \\
\text { de Baixa Renda no Contexto de Consumo de Crédito e } \\
\text { Violência Financeira }\end{array}$ \\
\hline EnANPAD & 2017 & $\begin{array}{c}\text { A Cultura e o Consumo de Crédito como (Re)Produtores de } \\
\text { Violência Financeira em Idosos: Identificando Lacunas e } \\
\text { Propostas de Trilhas de Investigação }\end{array}$ \\
\hline EnANPAD & 2017 & Motivações de Consumo e Identidade do Idoso Brasileiro \\
\hline EnANPAD & 2017 & $\begin{array}{l}\text { A Ressignificação da Terceira Idade: Redescobrindo Corpo, } \\
\text { Prazer, Vida e Sociabilidade na Dança de Salão }\end{array}$ \\
\hline EnANPAD & 2017 & $\begin{array}{l}\text { Uso das Tecnologias de Informação e Comunicação na } \\
\text { Terceira Idade: Um Estudo sobre Vulnerabilidade à } \\
\text { Engenharia Social }\end{array}$ \\
\hline EnANPAD & 2017 & $\begin{array}{l}\text { Qualidade de Vida Subjetiva de Idosos Residentes em } \\
\text { Instituições de Longa Permanência para Idosos }\end{array}$ \\
\hline $\begin{array}{l}\text { Revista Brasileira de } \\
\text { Pesquisa em Turismo }\end{array}$ & 2017 & $\begin{array}{c}\text { Aceitação e uso da tecnologia para escolha de destinos } \\
\text { turísticos por pessoas da Terceira Idade: um estudo usando a } \\
\text { UTAUT2 }\end{array}$ \\
\hline $\begin{array}{l}\text { REMARK - Revista } \\
\text { Brasileira de } \\
\text { Marketing } \\
\end{array}$ & 2016 & $\begin{array}{c}\text { Além das Aparências: um Estudo sobre a Identidade de Idade } \\
\text { de Mulheres na Terceira Idade }\end{array}$ \\
\hline EMA & 2016 & $\begin{array}{c}\text { Velho, Eu? Comportamento Materialista e Suas Relações entre } \\
\text { Consumidores Maduros e Idosos }\end{array}$ \\
\hline EMA & 2016 & $\begin{array}{c}\text { Pistas Sociais no Varejo e Avaliações Desfavoráveis aos } \\
\text { Idosos. O Valor Preditivo das Atitudes em Ambientes } \\
\text { Varejistas }\end{array}$ \\
\hline EMA & 2016 & $\begin{array}{l}\text { O Envelhecer para Mulheres Maduras: Valores Pessoais de } \\
\text { Senescentes Graduais Quanto ao Uso do Cosmético Facial } \\
\text { Antienvelhecimento }\end{array}$ \\
\hline $\begin{array}{l}\text { RAC - Revista de } \\
\text { Administração } \\
\text { Contemporânea }\end{array}$ & 2016 & $\begin{array}{c}\text { Trajetórias de Consumo: O Sujeito-Consumidor de Serviços } \\
\text { Bancários na Terceira Idade }\end{array}$ \\
\hline EnANPAD & 2015 & $\begin{array}{l}\text { O Bem-Estar ao Comprar no Contexto dos Shopping Centers: } \\
\text { um Estudo com Idosos }\end{array}$ \\
\hline EnANPAD & 2015 & $\begin{array}{l}\text { A Contribuição da Internet na Melhoria da Qualidade de Vida } \\
\text { Subjetiva do Idoso }\end{array}$ \\
\hline EnANPAD & 2015 & $\begin{array}{l}\text { Experiência Vivenciada por Idosos em Suas Visitas a um } \\
\text { Shopping Center: Proposição de um Modelo Teórico }\end{array}$ \\
\hline $\begin{array}{l}\text { Revista Brasileira de } \\
\text { Gestão de Negócios }\end{array}$ & 2015 & Atitude de mulheres maduras em relação a fotos de moda \\
\hline $\begin{array}{l}\text { RAE - Revista de } \\
\text { Administração de } \\
\text { Empresas }\end{array}$ & 2013 & $\begin{array}{l}\text { O novo consumidor idoso: identificação dos atributos } \\
\text { varejistas relevantes }\end{array}$ \\
\hline $\begin{array}{l}\text { Revista Brasileira de } \\
\text { Pesquisa em Turismo }\end{array}$ & 2013 & Os tempos da viagem para os idosos \\
\hline
\end{tabular}




\begin{tabular}{|c|c|c|}
\hline $\begin{array}{l}\text { REA Revista de } \\
\text { Administração da } \\
\text { UFSM }\end{array}$ & 2013 & $\begin{array}{c}\text { As emoções dos consumidores da terceira idade no processo de } \\
\text { escolha de destinos de viagens }\end{array}$ \\
\hline EnANPAD & 2012 & $\begin{array}{l}\text { Valores Pessoais de Idosos Usuários de Academias: Uma } \\
\text { Análise Sob a Perspectiva da Teoria da Cadeia Meios-Fim }\end{array}$ \\
\hline EnANPAD & 2012 & $\begin{array}{l}\text { Processo de Escolha de Alimentos por parte de Consumidores } \\
\text { Idosos }\end{array}$ \\
\hline EnANPAD & 2012 & $\begin{array}{l}\text { A Influência dos Fatores de Design do Ambiente de Loja na } \\
\text { Interação Consumidor-consumidor: um Estudo junto a } \\
\text { Consumidores de Terceira Idade no Varejo Supermercadista }\end{array}$ \\
\hline EMA & 2012 & $\begin{array}{l}\text { A Internet e a Terceira Idade: Elaboração de um Modelo } \\
\text { Teórico para a Compreensão deste Comportamento de } \\
\text { Consumo }\end{array}$ \\
\hline $\begin{array}{l}\text { Revista Turismo Visão } \\
\text { e Ação }\end{array}$ & 2012 & $\begin{array}{c}\text { Passeios Turísticos como Estratégia de Prevenção e } \\
\text { Recuperação da Saúde Mental em Idosos }\end{array}$ \\
\hline $\begin{array}{l}\text { REMARK - Revista } \\
\text { Brasileira de } \\
\text { Marketing } \\
\end{array}$ & 2011 & $\begin{array}{c}\text { Atividades Física, Educativa e de Dança: Um Estudo dos } \\
\text { Valores Pessoais dos Consumidores Idosos }\end{array}$ \\
\hline Turismo em Análise & 2010 & $\begin{array}{c}\text { A Viagem e a Memória do Idoso: um estudo na região da Serra } \\
\text { Gaúcha }\end{array}$ \\
\hline Turismo em Análise & 2010 & $\begin{array}{l}\text { Turismo e Idosos: o patrimônio imaterial como fator de atração } \\
\text { para o turismo cultural no espaço rural }\end{array}$ \\
\hline ENGPR & 2009 & $\begin{array}{c}\text { A Invisibilidade dos Idosos: O Estigma Imputado aos Mais } \\
\text { Velhos e Suas Implicações em Centro Comercial de Porto } \\
\text { Alegre }\end{array}$ \\
\hline EnANPAD & 2009 & A Moda para a Consumidora da Terceira Idade \\
\hline EnANPAD & 2009 & $\begin{array}{c}\text { Impactos Físicos, Cognitivos e Sociais do Uso da Internet por } \\
\text { Idosos: um Estudo Netnográfico em Redes de Comunicação } \\
\text { Online }\end{array}$ \\
\hline $\begin{array}{l}\text { Revista Turismo Visão } \\
\text { e Ação }\end{array}$ & 2009 & $\begin{array}{c}\text { O Comportamento da Compra de Serviços de Turismo na } \\
\text { Terceira Idade }\end{array}$ \\
\hline EMA & 2008 & $\begin{array}{l}\text { O Significado da Terceira Idade pela Terceira Idade: } \\
\text { Autoconceito das Classes AB e CD em São Paulo }\end{array}$ \\
\hline EMA & 2008 & $\begin{array}{c}\text { A Ambientação da Loja de Varejo de Confecções para o } \\
\text { Mercado de Terceira Idade }\end{array}$ \\
\hline $\begin{array}{l}\text { Caderno Virtual de } \\
\text { Turismo (UFRJ) }\end{array}$ & 2008 & $\begin{array}{l}\text { Perspectiva do turismo de lazer para a terceira idade no lugar } \\
\text { Ponta da Tulha - Ilhéus - Bahia }\end{array}$ \\
\hline Turismo em Análise & 2008 & $\begin{array}{l}\text { Entendendo as Atitudes da Terceira Idade das Classes A e B de } \\
\text { São Paulo em Relação ao Turismo }\end{array}$ \\
\hline
\end{tabular}

Fonte: Dados da pesquisa (2021).

A análise dos dados foi realizada a partir de uma leitura dos 35 artigos selecionados. Foram feiras as seguintes análises: (1) Evolução quantitativa da publicação de artigos sobre o consumidor da terceira idade nos últimos 10 anos; (2) Mapeamento das universidades e autores que produziram sobre o consumidor da terceira idade; (3) Mapeamento dos artigos publicados por somente um autor ou em coautoria; (4) Mapeamento das metodologias utilizadas nos artigos selecionados; (5) Análise das temáticas investigadas nos artigos selecionados. 


\section{RESULTADOS E DISCUSSÕES}

Foram 35 artigos publicados no período de 2008 a 2017 em revistas classificadas no Qualis A1-B1 em Administração e nos anais de encontros da ANPAD. Vale ressaltar que, dentre as revistas listadas na área de Administração, também estão revistas de outras áreas e revistas classificadas como interdisciplinar. Foram consideradas as revistas de outras áreas (já que estão listadas no Qualis de Administração) que continham artigos sobre a temática de consumo, como o caso das revistas voltadas ao turismo. O quadro 2 apresenta a quantidade de artigos publicados por revista/congresso.

Quadro 2 - Revistas e Congressos com artigos sobre o consumo na terceira idade

\begin{tabular}{|c|c|}
\hline Evento e revista & Total de artigos \\
\hline EnANPAD & 14 \\
\hline EMA - Encontro de Marketing da ANPAD & 6 \\
\hline Turismo em Análise & 3 \\
\hline REMARK - Revista Brasileira de Marketing & 2 \\
\hline Revista Brasileira de Pesquisa em Turismo & 2 \\
\hline Revista Turismo Visão e Ação & 2 \\
\hline Caderno Virtual de Turismo (UFRJ) & 1 \\
\hline ENGPR - Encontro de Gestão de Pessoas e Relações de Trabalho & 1 \\
\hline RAC - Revista de Administração Contemporânea & 1 \\
\hline RAE - Resista de Administração de Empresas & 1 \\
\hline REA - Revista de Administração da UFSM & 1 \\
\hline Revista Brasileira de Gestão de Negócios & 1 \\
\hline Total de artigos & $\mathbf{3 5}$ \\
\hline
\end{tabular}

Fonte: Dados da pesquisa (2021).

O congresso EnANPAD foi o que mais apresentou publicações de artigos sobre o consumo na terceira idade. O congresso possui uma área só de Marketing que publica artigos sobre comportamento do consumidor e temáticas de consumo. O EMA, congresso da ANPAD voltado para a área de Marketing foi o segundo veículo que mais publicou sobre o tema.

Dentre as revistas científicas, podem-se destacar os periódicos dedicados à área de turismo. A revista Turismo em Análise, por exemplo, publicou três estudos sobre o consumidor da terceira idade. Portanto, a pesquisa sobre o turismo na terceira idade tem recebido atenção dos estudiosos. As revistas da área de turismo publicaram oito artigos sobre terceira idade, enquanto as da área de administração publicaram seis. 
Foi realizado um mapeamento da evolução quantitativa da publicação de artigos sobre o consumidor da terceira idade nos últimos 10 anos. No gráfico 1 é apresentada a quantidade de publicações por ano.

Gráfico 1 - Quantidade de artigos publicados por ano

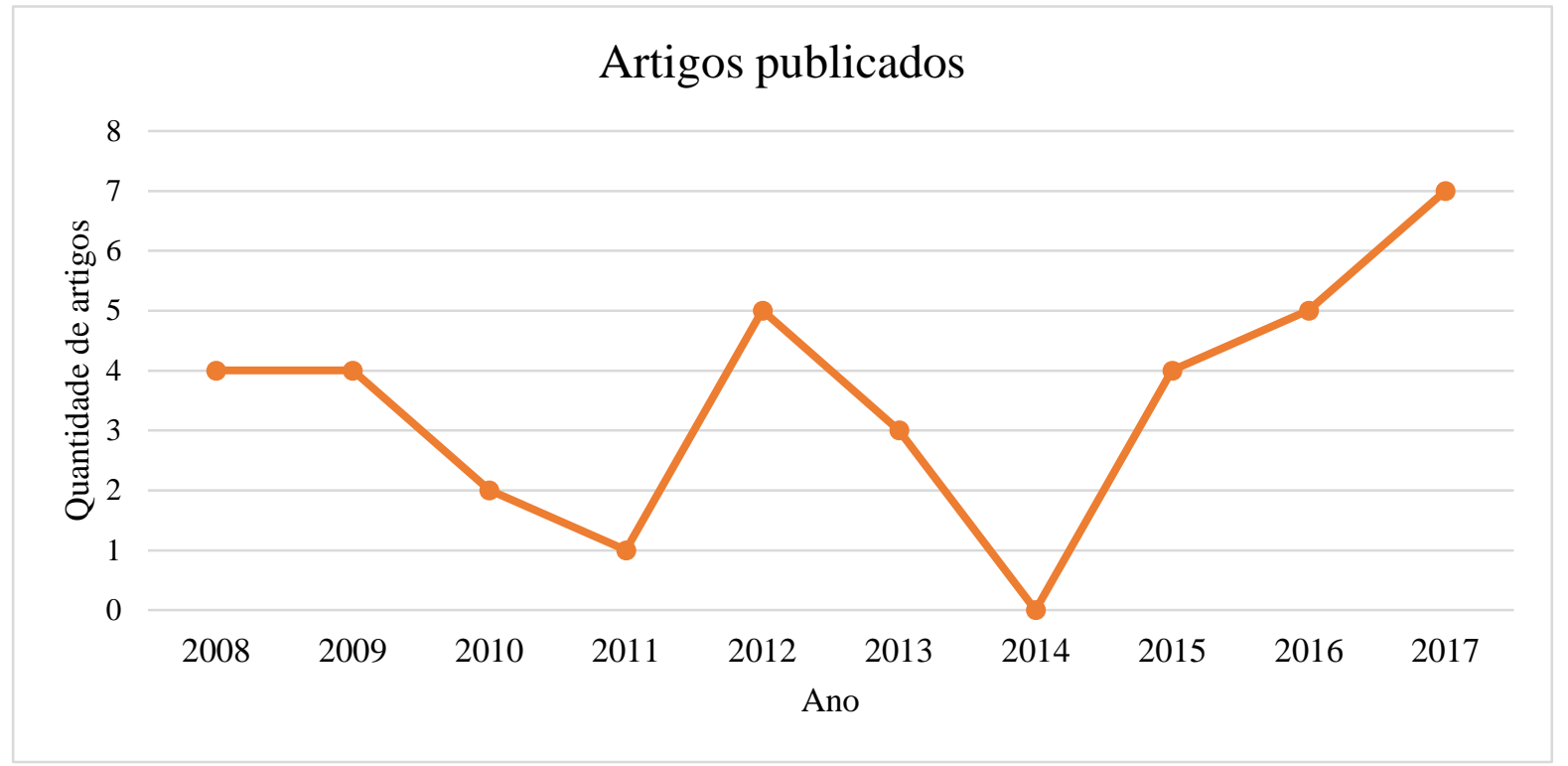

Fonte: Dados da pesquisa (2021).

Como pode ser visto no gráfico 1 , o ano de 2017 foi o que teve maior quantidade de artigos sobre a temática (sete artigos). Esse pico de produção foi puxado pelo EnANPAD, onde foram publicados nos anais do evento seis artigos. Os anos de 2016 e 2012 tiveram cinco artigos publicados em cada ano, também tendo como destaque os congressos EnANPAD e EMA (congresso de Marketing da ANPAD). Em 2014, não foram encontrados estudos sobre consumidor da terceira idade nos veículos pesquisados.

No geral, as pesquisas sobre o tema estão razoavelmente distribuídas ao longo dos anos. Os últimos cinco anos apresentaram uma quantidade de publicações um pouco maior que os cinco anos anteriores (Quadro 3), porém não é algo que chame a atenção para uma maior dedicação aos estudos nesse campo. Os encontros da ANPAD que impulsionaram essa maior publicação nos últimos anos. Seria interessante continuar monitorando as publicações sobre o tema para observar se de fato este está crescendo e recebendo mais atenção e dedicação dos pesquisadores. 
Quadro 3 - Artigos publicados por período

\begin{tabular}{|c|c|c|}
\hline Período & Total de artigos publicados & \% \\
\hline $2008-2012$ & 16 & $46 \%$ \\
\hline $2013-2017$ & 19 & $54 \%$ \\
\hline Total & $\mathbf{3 5}$ & $\mathbf{1 0 0 \%}$ \\
\hline
\end{tabular}

Fonte: Dados da pesquisa (2021).

Buscou-se também identificar a quantidade de artigos publicados por instituição de ensino, para mapear as instituições em que há pesquisadores dedicados ou que possuem interesse no estudo do consumidor da terceira idade. O quadro 4 apresenta esse resultado.

\begin{tabular}{|c|c|}
\hline \multicolumn{2}{|c|}{ Quadro 4 - Principais Instituições que publicaram artigo } \\
\hline Instituição de ensino & Número de artigos \\
\hline Pontifícia Universidade Católica de Minas Gerais - PUC-MG & 4 \\
\hline Universidade Federal do Rio Grande do Sul - UFRGS & 4 \\
\hline Escola Superior de Propaganda e Marketing - ESPM & 3 \\
\hline Instituto Federal de Educação, Ciência e Tecnologia do Rio Grande do Sul & 3 \\
\hline Pontifícia Universidade Católica do Rio Grande do Sul - PUC-RS & 3 \\
\hline Universidade Nove de Julho - UNINOVE & 3 \\
\hline Pontifícia Universidade Católica do Rio de Janeiro - PUC-Rio & 2 \\
\hline Universidade Federal da Paraíba - UFPB & 2 \\
\hline Universidade Presbiteriana Mackenzie & 2 \\
\hline
\end{tabular}

Fonte: Dados da pesquisa (2021).

Se um artigo era de autoria de pesquisadores de uma determinada instituição de ensino, essa instituição recebia a pontuação de um artigo publicado. Caso o artigo fosse de autoria de pesquisadores de diferentes instituições de ensino, cada uma delas também recebia a pontuação de um artigo publicado. Em seguida, realizou-se a soma para verificar as instituições mais envolvidas nessas publicações.

Como pode ser visto no quadro 4, a PUC-Minas e a UFRGS são as universidades que mais publicaram artigos sobre o consumidor da terceira idade no período dos 10 anos pesquisados. Cada uma publicou quatro estudos.

Além de mapear as instituições de ensino que já publicaram artigos nessa área de concentração, buscou-se listar o nome dos autores desses artigos. O Quadro 5 apresenta os autores que já publicaram no mínimo um artigo sobre o tema nos últimos 10 anos. Quando um artigo tinha autoria de somente um autor, o mesmo ganhava a pontuação de uma publicação, quando era publicado por mais de um autor, cada um ganhava igualmente um ponto. 
Quadro 5 - Principais autores que publicaram artigos sobre o tema

\begin{tabular}{|c|c|c|}
\hline Autores & Número de artigos & Instituição de ensino \\
\hline Marcelo de Rezende Pinto & 3 & PUC-MG \\
\hline Luiz Antonio Slongo & 3 & UFRGS \\
\hline Priscila Silva Esteves & 3 & UFRGS e IFRS \\
\hline Gustavo Tomaz de Almeida & 2 & PUC-MG \\
\hline Cláudio Hoffmann Sampaio & 2 & PUC-RS \\
\hline Marcelo Gattermann Perin & 2 & PUC-RS \\
\hline Marise Mainieri de Ugalde & 2 & PUC-RS e ESPM \\
\hline Renato Hübner Barcelos & 2 & UFRGS \\
\hline Maria de Lourdes Bacha & 2 & Universidade Presbiteriana Mackenzie \\
\hline
\end{tabular}

Fonte: Dados da pesquisa (2021).

De acordo com o quadro 5, os autores que mais se dedicaram ao tema nos últimos 10 anos são Marcelo de Rezende Pinto da PUC-Minas, Luiz Antonio Slongo da UFRGS e Priscila Silva Esteves da UFRGS e Instituto Federal de Educação, Ciência e Tecnologia do Rio Grande do Sul. A PUC-Minas e a UFRGS foram as universidades mais prolíficas e esses pesquisadores foram responsáveis pelo destaque dessas instituições. Destacam-se em seguida os pesquisadores: Gustavo Tomaz de Almeida (PUC-Minas), Cláudio Hoffmann Sampaio (PUC-RS), Marcelo Gattermann Perin (PUC-RS), Marise Mainieri de Ugalde (PUC-RS e ESPM), Renato Hübner Barcelos (UFRGS) e Maria de Lourdes Bacha (Universidade Presbiteriana Mackenzie).

A maior parte dos artigos foi publicada em coautoria. Quase metade dos artigos foi escrita por dois autores. Também houve um número razoável de artigos publicados por quatro autores em conjunto. Somente dois artigos tiveram autoria única, como pode ser visto no quadro 6.

\begin{tabular}{|c|c|c|}
\multicolumn{3}{|c|}{ Quadro 6 - Autoria e coautoria } \\
\hline Número de autores & Número de artigos & $\%$ \\
\hline 1 autor & 2 & $6 \%$ \\
\hline 2 autores & 17 & $49 \%$ \\
\hline 3 autores & 4 & $11 \%$ \\
\hline 4 autores & 9 & $26 \%$ \\
\hline 5 autores & 3 & $9 \%$ \\
\hline TOTAL & $\mathbf{3 5}$ & $\mathbf{1 0 0 \%}$ \\
\hline
\end{tabular}

Fonte: Dados da pesquisa (2021).

Em relação à metodologia adotada pelas publicações selecionadas, a maioria realizou uma pesquisa qualitativa, utilizando métodos como etnografia ou entrevista em profundidade. Em seguida, destacaram-se as pesquisas de natureza quantitativa, como exemplos o 
levantamento e o experimento. Em menor destaque estão as pesquisas teóricas, como ensaios teóricos, e as pesquisas quali e quanti, como exemplo, pesquisas que começam com uma etapa qualitativa e depois utilizam um levantamento. O quadro 7 apresenta esses resultados.

\section{Quadro 7 - Metodologia dos artigos}

\begin{tabular}{|c|c|c|}
\hline Tipo de metodologia & Número de artigos & \% \\
\hline Teórico & 3 & $9 \%$ \\
\hline Qualitativo & 19 & $54 \%$ \\
\hline Quantitativo & 10 & $29 \%$ \\
\hline Qualitativo e Quantitativo & 3 & $9 \%$ \\
\hline TOTAL & $\mathbf{3 5}$ & $\mathbf{1 0 0 \%}$ \\
\hline
\end{tabular}

Fonte: Dados da pesquisa (2021).

Por fim, buscou-se identificar as temáticas abordadas nos artigos selecionados. Por haver muitas revistas voltadas para o turismo, a maior parte dos temas investigados compreende o turismo na terceira idade. Parece haver uma preocupação em entender melhor esse consumidor que pode contribuir com grandes ganhos financeiros para o setor turístico. De fato, estudos têm sido realizados para investigar o turismo na terceira idade, pois, de acordo com Horneman et al. (2002), o consumidor na terceira idade está mais aberto a viagens e atividades de lazer em geral. É um consumidor que tem o desejo de aproveitar o tempo livre de que dispõe (DOLL, 2007).

Outro tema em destaque nas publicações analisadas envolve o uso de tecnologia pelo consumidor da terceira idade. Entender como esse público se relaciona com a tecnologia, em especial a internet, mostra-se uma preocupação real, já que hoje o mundo está conectado e é preciso entender como a terceira idade se posiciona nesse cenário. Um dos artigos inclusive investiga o uso de tecnologia pela terceira idade para escolher o destino turístico, mostrando o quanto esses dois temas (tecnologia e turismo) se destacaram entre as pesquisas selecionadas. Outro tema bastante abordado nos artigos foi sobre o ambiente e os atributos importantes no varejo. Parece haver um interesse em saber como o varejo é visto pela terceira idade. Por ser um público com tempo livre (DOLL, 2007) e que possui uma renda para gastar proveniente da aposentadoria (SILVA, 2008), passa a ser um público-alvo interessante e com potencial como consumidor. Entender suas necessidades e desejos passa a ser importante para as empresas oferecerem o que eles querem e influenciar em suas escolhas de marca (MYERS; LUMBERS, 2008; PETTIGREW; MIZERSKI; DONOVAN, 2005; LAMBERTPANDRAUD; LAURENT, 2010).

Além desses três temas em destaque (turismo, tecnologia e varejo), outros também foram abordados em mais de um artigo, a saber: consumo e identidade, valores do 
consumidor, a moda na terceira idade, consumo de crédito e serviços bancários, qualidade de vida (na temática do consumo), consumo em shopping center e consumo de atividades de lazer. Alguns autores têm dado ênfase ao consumo de atividades de lazer, pois são atividades valorizadas pelo segmento da terceira idade (BURNETT-WOLLE; GODBEY, 2007).

Por fim, algumas temáticas foram investigadas em somente um artigo como o consumo de alimentos, a invisibilidade dos idosos, o materialismo e o consumo de cosméticos.

\section{CONSIDERAÇÕES FINAIS}

O presente estudo buscou analisar a produção científica no campo do comportamento do consumidor da terceira idade no Brasil. Nesse contexto, foi realizada uma pesquisa bibliométrica. Foram selecionados 35 artigos publicados nos congressos da ANPAD e nas revistas nacionais classificadas no Qualis de Administração como A1 - B1. O período analisado consistiu nos últimos dez anos, isto é, de 2008 a 2017. O estudo buscou analisar se houve uma evolução quantitativa das publicações de artigos sobre o consumidor da terceira idade nos últimos 10 anos; quais são as universidades e os autores que produziram sobre o tema; quantos artigos foram escritos por somente um autor ou em coautoria; quais foram as metodologias utilizadas; e quais as temáticas abordadas nos artigos selecionados.

Foi observado que a publicação de artigos sobre o consumidor da terceira idade foi distribuída ao longo dos últimos 10 anos, porém em 2017 houve um boom de publicações puxado pelo EnANPAD. As revistas voltadas para o turismo também tiveram destaque na pesquisa sobre o consumidor da terceira idade, em especial o turismo na terceira idade.

Dentre as universidades mais prolíficas estão a PUC-Minas e a UFRGS. Os autores mais prolíficos foram Marcelo de Rezende Pinto, Luiz Antonio Slongo e Priscila Silva Esteves, que foram os responsáveis por colocar em evidência as universidades mais produtivas no tema da terceira idade.

A maioria dos artigos foi escrita em coautoria de dois autores. Vale ressaltar que somente dois artigos foram escritos por um único autor.

A pesquisa qualitativa foi a mais utilizada nos artigos selecionados, com destaque para a entrevista em profundidade, seguida da pesquisa quantitativa, com destaque para o levantamento. Poucos artigos desenvolveram uma pesquisa quali-quanti ou um ensaio teórico.

Dentre as temáticas mais abordadas na produção científica analisada estão o turismo na terceira idade (por haver muitas revistas voltadas especificamente para o turismo), o uso de 
tecnologia pelo consumidor da terceira idade, em especial a internet, e o ambiente e os atributos importantes no varejo.

O presente artigo traz contribuições para a área de estudo da terceira idade, visto que faz um mapeamento da produção científica desse campo de pesquisa. Levantar quantos artigos foram publicados sobre o assunto, bem como quais universidades e autores se dedicam ou se interessam pelo tema e o que se tem investigado sobre o consumidor da terceira idade auxiliam o meio acadêmico a mapear o campo e definir novos caminhos de pesquisa.

O consumidor da terceira idade, apesar de ser um público relevante, ainda não tem recebido a atenção que merece dos estudiosos do consumo e comportamento do consumidor. Portanto, é preciso desenvolver novas pesquisas sobre o público-alvo e dar continuidade às pesquisas existentes. Sugere-se continuar mapeando a produção científica na área e acompanhar se o campo de estudo está crescendo e despertando mais interesse dos pesquisadores.

\section{REFERÊNCIAS}

ACUÑA, R. Anything but Mexican: Chicanos in Contemporary Los Angeles. New York: Verso, 2004.

AHUVIA, A. C. Beyond the extended self: loved objects and consumers' identity narratives. Journal of Consumer Research, v. 32, n. 1, p. 171-84. 2005.

ALEXANDRIS, K.; CARROLL, B. An analysis of Leisure Constraints Based on Different Recreational Sport Participation Levels: Results from a study in Greece. Leisure Sciences, v. 19, n. 1, p. 1-15, 1997.

ALVES, A. M. Fazendo antropologia no baile: uma discussão sobre observação participante. In: VELHO, G.; KUSCHNIR, K. (org.). Pesquisas urbanas: desafio do trabalho antropológico. Rio de Janeiro: Zahar, 2003. p. 174-189.

ARAUJO, F. F.; CASOTTI, L. M.; SILVA, R. C. M.; PESSÔA, L. A. G. P. O Consumidor de Terceira Idade na Primeira Década do Século XXI: Uma Análise da Propaganda Dirigida a Idosos. Revista Administração em Diálogo, v. 17, p. 54-85, 2015.

ARAUJO, F. F.; ROCHA, A. Significados Atribuídos ao Lazer na Terceira Idade: Observação Participante em Encontros Musicais. Podium: sport, leisure and tourism review, v. 5, n. 2, p. 38-55, 2016.

ARAUJO, F. F.; ROCHA, A. Ressignificação da Terceira Idade: Redescobrindo Corpo, Prazer, Vida e Sociabilidade na Dança de Salão. In: XLI ENCONTRO DA ANPAD, Anais.. São Paulo: ANPAD, 2017. 
BABIN, B. J.; ZHUANG, W.; BORGES, A. Managing service recovery experience: effects of the forgiveness for older consumers. Journal of Retailing and Consumer Services, v. 58, n. $102222,2021$.

BARNHART, M.; PEÑALOZA, L. Who are you calling old? Negotiating old age identity in the elderly consumption ensemble. Journal of Consumer Research, v. 39, n. 6, p. 1133$1153,2013$.

BINSTOCK, R.H. Old Age Policies, Politics, and Ageism. Generations, v. 29, n. 3, p. 73-78, 2005.

BIRTWISTLE, G.; TSIM, C. Consumer Purchasing Behavior: An Investigation of the UK Mature Women's Clothing Market. Journal of Consumer Behavior, v. 4, n. 6, p. 453-464, 2005.

BURNETT-WOLLE, S.; GODBEY, G. Refining research on older adults' leisure: implication of selection, optimization, and compensation and socioemotional selectivity theories. Journal of Leisure Research, v. 39, n. 3, p. 498-513, 2007.

BURT, S.; GABBOTT, M. The Elderly Consumer and Non-Food Purchase Behaviour. European Journal of Marketing, v. 29, n. 2, p. 43-57, 1995.

CASTRO, J. Is That You on TV, Grandpa? Time, mar., p. 53, 1989.

CERVO, A. L.; BERVIAN, P. A.; DA SILVA, R. Metodologia Científica. 6. ed. São Paulo: Pearson Prentice Hall, 2007.

COLE, C.; LAURENT, G.; DROLET, A.; EBERT, J.; GUTCHESS, A.; LAMBERTPANDRAUD, R.; MULLET, E.; NORTON, M.; PETERS, E. Decision Making and Brand Choice by Older Consumers. Marketing Letters, v. 19, n. 3/4, p. 355-365, 2008.

CUDDY, A. J. C.; NORTON, M. I.; FISKE, S. T. This Old Stereotype: The Stubbornness and Pervasiveness of the Elderly Stereotype. Journal of Social Issues, v. 61, n. 2, p. 267-285, 2005.

CUMMING, E.; HENRY, W. E. Growing Old: The Process of Disengagement. New York: Basic, 1961.

DEBERT, G. G. A Invenção da Terceira Idade e a Rearticulação de Formas de Consumo e Demandas Políticas. Revista Brasileira de Ciências Sociais, v. 12, n. 34, p. 39-56, 1997.

DEBERT, G. G. A Reinvenção da Velhice: Socialização e Processos de Reprivatização do Envelhecimento. São Paulo: Universidade de São Paulo. FAPESP, 2004.

DOLL, J. Educação, cultura e lazer: perspectivas de velhice bem-sucedida. In: NERI, A. L. (org.). Idosos no Brasil: vivências, desafios e expectativas na Terceira Idade. São Paulo: Fundação Perseu Abramo; SESC, p. 109-124, 2007.

FABRICIUS, S.; ERIKSSON, N. Young-elderly individuals' use of social media for travel purpose. Tourism \& Management Studies, v. 13, n. 1, p. 27-32, 2017. 
FENNELl, G.; PHILliPSON, C.; EVERS, H. The Sociology of Old Age. Philadelphia: Open University Press, 1988.

FLEISCHER, A.; PIZAM, A. Tourism Constraints among Israeli Seniors. Annals of Tourism Research, v. 29, n. 1, p. 106-123, 2002.

FONTENLA, J. C. E.; ALMEIDA, L. F. de. A importância do boca a boca positivo no consumo de serviços de lazer pela terceira idade. RBGN: Revista Brasileira de Gestão de Negócios, v. 22, n. 3, p. 750-780, 2020.

GERGEN, K.; GERGEN M. M. The New Aging: Self-Construction and Social Values. In: SCHAIE, K.W.; HENDRICK, J. The Evolution of the Aging Self: The Societal Impact on the Aging Process. New York: Springer, p. 281-306, 2000.

GIL, A. C. Métodos e Técnicas de Pesquisa Social. 6. ed. São Paulo: Atlas, 2008.

GILLY, M. C.; ENIS, B. M. Recycling the Family Life Cycle: A Proposal for Redefinition. Advances in Consumer Research, v. 9, MI: Association for Consumer Research, p. 271-276, 1982.

GOLDENBERG, M. Corpo, Envelhecimento e Felicidade. Rio de Janeiro: Civilização Brasileira, p. 109-131, 2011.

GULlETTE, M.M. Aged by Culture. Chicago: University of Chicago Press, 2004.

HALL, S. Representation: Cultural Representation and Signifying Practices. London: Open University Press, 1997.

HOEYMANS, N.; FESKENS, E. J. M.; VAN DEN BOS, G. A. M.; KROMHOUT, D. Age, Time, and Cohort Effects on Functional Status and Self-Rated Health in Elderly Men. American Journal of Public Health, v. 87, n. 10, 1997.

HORNEMAN, L.; CARTER, R.W.; WEI, S.; RUYS, H. Profiling the senior traveler: an Australian Perspective. Journal of Travel Research, v. 41, p. 23-37, 2002.

IBGE - INSTITUTO BRASILEIRO DE GEOGRAFIA E ESTATÍSTICA. Censo 2010. Estudos e Pesquisa. Instituto Brasileiro de Geografia e Estatística. Rio de Janeiro, 2010. Disponível em: http://www.ibge.gov.br. Acesso em 16 jan. 2020.

JANMOHAMED, A.; LlOYD, D. The Nature and Context of Minority Discourse. Oxford: Oxford University Press, 1990.

KENNETT, P. A.; MOSCHIS, G. P.; BELLENGER, D. N. Marketing Financial Services to Mature Consumers. Journal of Services Marketing, v. 9, n. 2, p. 62-72, 1995.

LAMBERT-PANDRAUD, R.; LAURENT, G. Why do older consumers buy older brands? The role of attachment and declining innovativeness. Journal of Marketing, v. 74, n. 5, p. 104-121, 2010.

LINS DE BARROS, M.M. Dossiê: velhice, família, Estado e propostas políticas. In: Sesc. Sinais sociais. 22a ed. Rio de Janeiro: Sesc Departamento Nacional, p. 9-14, 2013. 
MATTILA, M.; KARJALUOTO, H.; PENTO, T. Internet Banking Adoption Among Mature Customers: Early Majority or Laggards? Journal of Services Marketing, v. 17, n. 5, p. 514$528,2003$.

MIGDAŁ-NAJMAN, K.; NAJMAN, K.; BADOWSKA, S. The GNG neural network in analyzing consumer behaviour patterns: empirical research on a purchasing behaviour processes realized by the elderly consumers. Advances in Data Analysis and Classification, v. 14, p. 947-982, 2020.

MURPHY, P. E.; STAPLES W. A. A Modernized Family Life Cycle. Journal of Consumer Research, v. 6, p. 12-22, 1979.

MYERS, H.; LUMBERS, M. Understanding older shoppers: a phenomenological investigation. Journal of Consumer Marketing, v. 25, n. 5, p. 294-301, 2008.

NASCO, S. A.; HALE D. Information Search for Home, Medical, and Financial Services by Mature Consumers. Journal of Services Marketing, v. 23, n. 4, p. 226-235, 2009.

NIKOU, S. Mobile Technology and forgotten consumers: The Young elderly. International Journal of Consumer Studies, v. 39, p. 294-304, 2015.

OBERG, P.; TORNSTAM, L. Body Images among Men and Women of Different Ages. Ageing and Society, v. 19, p. 629-644, 1999.

PAK, C.; KAMBIL, A. Over 50 and Ready to Shop - Serving the Aging Consumer. Journal of Business Strategy, v. 27, n. 6, p. 18-28, 2006.

PANNHORST, M.; DOST, F. Marketing innovations to old-age consumers: A dynamic Bass model for different life stages. Technological Forecasting and Social Change, v. 140, p. 315-327, 2019.

PETER, J. P.; OLSON, J. C. Comportamento do consumidor e estratégia de marketing. São Paulo: McGraw-Hill, 2009.

PETTIGREW, S.; MIZERSKI K.; DONOVAN, R. The Three 'Big Issues' for Older Supermarket Shoppers. Journal of Consumer Marketing, v. 22, n. 6, p. 306-312, 2005.

SANTOS, R. N. M. dos. Produção científica: por que medir? O que medir?. Revista Digital de Biblioteconomia e Ciência da Informação, v. 1, n. 1, p. 22-38, 2003.

SCHEWE, C.; CARLSON, B. Age Matters: Segmenting Swedish Markets by Generational Cohorts. Lund Institute of Economic Research. Working Paper Series. Sweden: Institute of Economic Research of Lund University, 2003.

SILVA, L. R. F. Da velhice à terceira idade: o percurso histórico das identidades atreladas ao processo de envelhecimento. História, Ciências, Saúde - Manguinhos, Rio de Janeiro, v. 15, n. 1, p. 155-168, 2008.

SWIMBERGHE, K.; DARRAT, M. A.; BEAL, B. D.; ASTAKHOVA, M. Examining a psychological sense of brand community in elderly consumers. Journal of Business Research, v. 82, p. 171-178, 2018. 
TOMAS, J. B.; PETERS, C. L. Silver seniors: Exploring the self-concept, lifestyles, and apparel consumption of women over age 65. International Journal of Retail \& Distribution Management, v. 37, n. 12, p. 1018-1040, 2009.

VESPERI, M. Forty-Nine Plus: Shifting Images of Aging in the Media. In: Reinventing Aging: Baby Boomers and Civic Engagement. Boston: Center for Health Communication, Harvard School of Public Health, 2004.

WELLS, W. C.; GUBAR G. Life Cycle Concept in Marketing Research. Journal of Marketing Research, v. 3, n. 4, p. 355-363, 1966.

WILLIAMS, P.; DROLET, A. Age-Related Differences in Responses to Emotional Advertisements. Journal of Consumer Research, v. 32, n. 3, p. 343-354, 2005.

\section{Como Referenciar este Artigo, conforme ABNT:}

ROCHA, M. C. V; PAULA, R. C. M. S; ARAÚJO, F. F; CASTRO, M. C. D; DUARTE. A. L. F. Consumidor da Terceira Idade: Estudo Bibliométrico dos Artigos Publicados no Brasil. Rev. FSA, Teresina, v.18, n. 03, art. 1, p. 3-28, mar. 2021.

\begin{tabular}{|l|c|c|c|c|c|}
\hline \multicolumn{1}{|c|}{ Contribuição dos Autores } & $\begin{array}{c}\text { M. C. V. } \\
\text { Rocha }\end{array}$ & $\begin{array}{c}\text { R. C. M. S. } \\
\text { Paula }\end{array}$ & $\begin{array}{c}\text { F. F. } \\
\text { Araújo }\end{array}$ & $\begin{array}{c}\text { M. C. D. } \\
\text { Castro }\end{array}$ & $\begin{array}{c}\text { A. L. F. } \\
\text { Duarte }\end{array}$ \\
\hline 1) concepção e planejamento. & $\mathrm{X}$ & & & & \\
\hline 2) análise e interpretação dos dados. & $\mathrm{X}$ & & $\mathrm{X}$ & & \\
\hline 3) elaboração do rascunho ou na revisão crítica do conteúdo. & & $\mathrm{X}$ & & & \\
\hline 4) participação na aprovação da versão final do manuscrito. & & & & $\mathrm{X}$ & $\mathrm{X}$ \\
\hline
\end{tabular}

